\title{
THE GREEN OCEAN AMAZON EXPERIMENT (GOAMAZON20I4/5) OBSERVES POLLUTION AFFECTING GASES, AEROSOLS, CLOUDS, AND RAINFALL OVER THE RAIN FOREST
}

S. T. Martin, P. Artaxo, L. Machado, A. O. Manzi, R. A. F. Souza, C. Schumacher, J. Wang, T. Biscaro, J. Brito, A. Calheiros, K. Jardine, A. Medeiros, B. Portela, S. S. de Sá, K. Adachi, A. C. Aiken, R. Albrecht, L. Alexander, M. O. Andreae, H. M. J. Barbosa, P. Buseck, D. Chand, J. M. Comstock, D. A. Day, M. Dubey, J. Fan, J. Fast, G. Fisch, E. Fortner, S. Giangrande, M. Gilles, A. H. Goldstein, A. Guenther, J. Hubbe, M. Jensen, J. L. Jimenez, F. N. Keutsch, S. Kim, C. Kuang, A. Laskin, K. McKinney, F. Mei, M. Miller, R. Nascimento, T. Pauliquevis, M. Pekour, J. Peres, T. Petäjä, C. Pöhlker, U. Pöschl, L. Rizzo, B. Schmid, J. E. Shilling, M. A. Silva Dias, J. N. Smith, J. M. Tomlinson, J. Tóta, and M. Wendisch

The susceptibility of air quality, weather, terrestrial ecosystems, and climate to human activities was investigated in a tropical environment.

A magnificent forest two-thirds the size of the continental United States follows the rhythms of the dry and wet seasons in the heart of South America (Salati and Vose 1984; Mares 1986; Garstang et al. 1990; Andreae et al. 2004; Keller et al. 2009; Davidson et al. 2012; Artaxo et al. 2013; ter Steege et al. 2013). The Amazon River, cutting the forest in half latitudinally near the equator, is more than $5 \mathrm{~km}$ wide in the narrowest sections during the dry season and expands to widths beyond $100 \mathrm{~km}$, as a river sea, in the widest sections during the wet season. It accounts for about $20 \%$ of the world's total flow of freshwater into the ocean. At least several thousand fish species swim in the waters of the Amazon basin, and on the order of 15,000 tree species populate its land. More than several hundred billion trees contribute to its immense carbon inventory.
Within this enormous, verdant expanse and excluding coastal urban zones on the margins lies a single major urban metropolitan area, the city of Manaus, meaning "Mother of the Gods" to the indigenous people. Founded by the Portuguese 350 years ago, the present-day metropolitan population is more than 2.5 million people. It is located in Amazonas, Brazil, a state of 3.5 million people, which has an area more than twice that of Texas, United States. Manaus is surrounded by undisturbed forest, with small-scale exceptions, for more than $1,500 \mathrm{~km}$ in all directions upwind and downwind of its emissions.

The history of Manaus is one of boom in the rubber years, complete with the import of European artisans to the "Paris of the Amazon," to bust thereafter to one of economic revival in recent decades (Grandin 2009). Manaus administered more than $90 \%$ of the world's 
rubber trade in 1900 but less than $5 \%$ by 1930 , largely as a result of the infamous actions of Englishman Henry Wickham. He surreptitiously transported the rubber seed from the Amazon to the Royal Botanic Gardens in London, eventually leading to the development of successful rubber plantations in Southeast Asia. The reverberations continue today with respect to rigorous requirements of scientific licenses for foreigners to do research in the Brazilian Amazon. As a consequence of the competition from plantation rubber in Asia, Manaus experienced an economic bust. The downturn was severe and sustained enough across several decades that public electricity was no longer available in Manaus by the 1950s, and only the affluent had private generators.

Starting in the 1960s, the ruling military government recognized the Amazon basin as a resource for exploitation and occupation. Manaus was designated as a free-trade zone and plans were developed for dams and long-distance paved roads. This vision has been partially realized in every extent over the past five decades and has guided the political dialogue surrounding the topics of the Amazon forest. Meanwhile, the economy of Manaus has accelerated and flourished again. Its population growth has averaged about $40 \%$ every 10 years since 1960 , and this rapid growth has been associated with equally rapid, though largely unplanned, changes in land use in the region (Fig. 1). Today, Manaus is a manufacturing pole within the Brazil economy.

GOAMAZON20I4/5 MOTIVATION. The residential, commercial, and industrial emissions of Manaus, aggregated as a pollution plume and carried westward by the equatorial trade winds, represent a unique laboratory to study the effect of human activities on air quality, weather, terrestrial ecosystems, and climate in a tropical, forested context (Kuhn et al. 2010; Trebs et al. 2012; Bateman et al. 2016; Liu et al. 2016; Martin et al. 2016). Worldwide, no other equivalent, large, urban area exists that is surrounded in all directions by primary tropical forests for $1,500 \mathrm{~km}$ and accessed largely only by boat or plane. The central Amazon in the wet season, absent Manaus, serves as a continental reference of atmospheric properties under background conditions (Andreae 2007), and the opportunity to study the effects of the Manaus plume in this environment represents a unique worldwide reference. At times, there are also episodic intrusions of background and polluted Atlantic and African air masses deep into the Amazon (Martin et al. 2010a). In the dry season regional- and continental-scale biomass burning can be significant (Artaxo et al. 2002).

The tropical context afforded by Manaus presents a unique and particularly important scientific opportunity. Compared to the temperate zones of Earth, tropical regions have been understudied. Historically, more research has been carried out in economically wealthier parts of the world, which are mostly located in the temperate band of the Northern Hemisphere. The tropics are anticipated to have a special role in the future of global air quality because population growth through 2050 is projected more for the tropical regions of Earth than elsewhere. Furthermore, the energy and hydrological cycles
AfFiliations: Martin, de SA, KeUtsch, And MCKinney-Harvard University, Cambridge, Massachusetts; Artaxo, Brito, AlbreCht, Barbosa, Peres, and Dias-University of São Paulo, São Paulo, Brazil; Machado, Biscaro, and Calmeiros-National Institute for Space Research, São José dos Campos, Brazil; ManzI ANd PoRTelA-National Institute of Amazonian Research, Manaus, Amazonas, Brazil; SouzA, Medeiros, and Nascimento-Amazonas State University, Amazonas, Brazil; SCHUMACHER-Texas A\&M University, College Station, Texas; Wang, Giangrande, Jensen, and KuANG-Brookhaven National Laboratory, Upton, New York; JARDINE AND GILLES—Lawrence Berkeley National Lab, Berkeley, California; ADACHI-Meteorological Research Institute, Tsukuba, Ibaraki, Japan; AIKEN AND DUBEY-Los Alamos National Laboratory, Los Alamos, New Mexico; AleXAnder, Chand, Comstock, Fan, Fast, Hubbe, Laskin, Mei, Pekour, Schmid, SHILLING, AND TomLINSON-Pacific Northwest National Laboratory, Richland, Washington; Andreae, PöhlKer, ANd PösChL-Max Planck Institute for Chemistry, Mainz, Germany; BUSECK-Arizona State University, Tempe, Arizona; DAY AND JIMENEZ-University of Colorado Boulder, Boulder, Colorado; FISCH-Aeronautic and Space Institute, São José dos Campos, Brazil; ForTnerAerodyne, Inc., Billerica, Massachusetts; GoLDSTEIN-University of California, Berkeley, Berkeley, California; GuentHer, KIM, AND SMITH-University of California, Irvine, Irvine, California; MillerRutgers, The State University of New Jersey, New Brunswick, New Jersey; PAuliQuevis AND Rizzo-Federal University of São Paulo, São Paulo, Brazil; Petäjä-University of Helsinki, Helsinki, Finland; TÓTA-Federal University of West Para, Santarém, Pará, Brazil; WENDISCH-University of Leipzig, Leipzig, Germany CORRESPONDING AUTHOR: S. T. Martin, scot_martin@harvard.edu

The abstract for this article can be found in this issue, following the table of contents.

DOI:I0.II75/BAMS-D-I5-0022I.I

A supplement to this article is available online (I0.II75/BAMS-D-15-0022I.2).

In final form 10 June 2016

(C2017 American Meteorological Society 
of the tropics, driven by the intense and sustained sunlight across this region, have critical roles in Earth's atmospheric circulation and climate. Any humaninduced changes to these cycles can have impacts over the entire Earth. Tropical forests also represent a series of important feedback responses in climate simulations, such as the response of net carbon storage to elevated carbon dioxide, to changed rainfall patterns, and to warmer temperatures, among other factors.

For these reasons, the Observations and Modeling of the Green Ocean Amazon 20142015 (GoAmazon2014/5) experiment was planned for the environs of Manaus. Williams et al. (2002) coined the phrase "Green Ocean" to emphasize the similarities between cloud
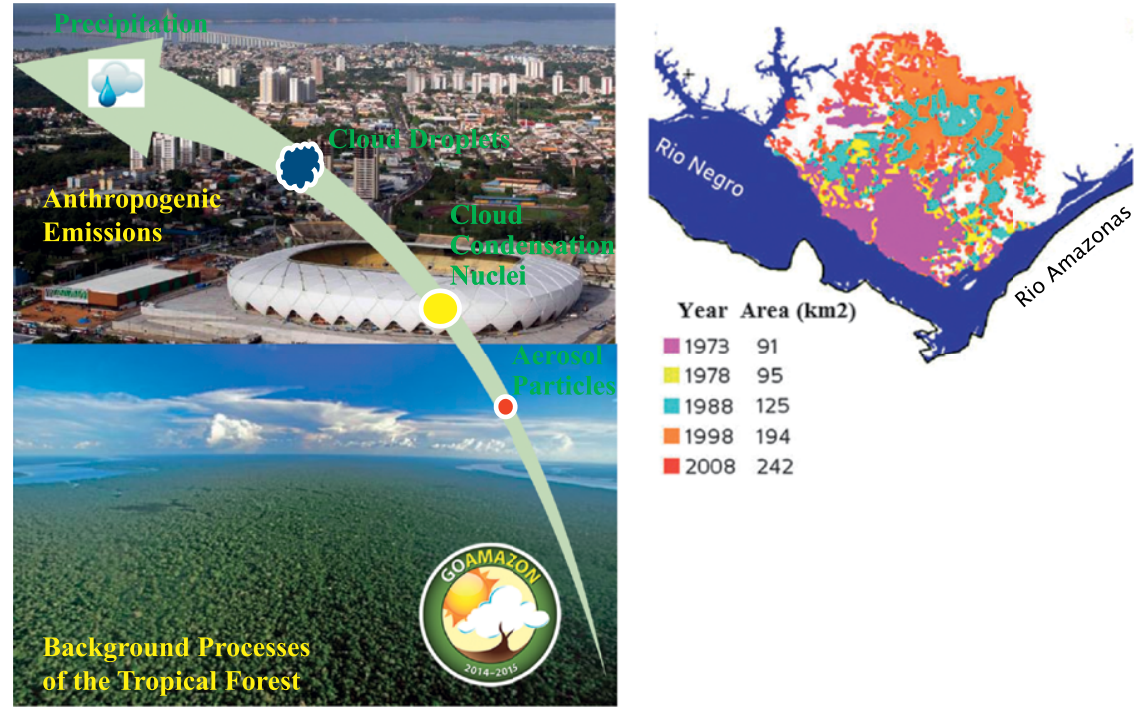

FIG. I. The GoAmazon2014/5 experiment in concept. (left) The advection by wind of a background air mass into Manaus, emissions into this air mass while over the city, and the transformation of atmospheric species as the air mass continues downwind of the urban region. The air mass is laden with biogenic volatile organic carbon compounds (BVOC) emitted by the forest both upwind and downwind of the city. These BVOCs are transformed by the atmospheric oxidant cycle into aerosol particles. The prevailing chemical reactions are altered by pollution. The particulate matter serves as CCN. As a result, cloud properties and possibly rainfall can be modified in response to different levels of pollution over the tropical rain forest. (right) As a surrogate for scaled anthropogenic emissions, the expansion of the urban region of Manaus $\left(-3.1^{\circ},-60.0^{\circ}\right)$, Brazil, across four decades is shown. The right panel is adapted from http://revistapesquisa.fapesp.br/wp-content/uploads/20 I / /\%78-08 | _ilhascalor_200.pdf, accessed II Aug 2015. properties over the Amazon

basin during the wet season and those over marine regions. In recent usage, the phrase has become more generalized to refer to atmospheric properties and processes over the verdant Amazon rain forest. In GoAmazon2014/5, Manaus and the surrounding background region served in combination as a laboratory to assess and understand the effects of human activities on air quality, weather, terrestrial ecosystems, and climate in a tropical context.

EXPERIMENT DESIGN. Easterlies associated with trade winds normally sweep the urban pollution plume westward. Contours of the modeled frequency distribution of flow trajectories of the Manaus pollution plume, representing a statistical description of flow in each season, are presented in Fig. 2. Driven by the easterlies of the trade winds, the plume crosses the river and first intersects the site T2, which is located just across the Rio Negro. The locations of the research sites around Manaus as well as several associated photos are shown in Fig. 3. In the wet season, although the pollution outflow from
Manaus most frequently continues southwesterly, $40 \%$ of the time it is modeled to go westerly toward the main ground research site T3. In the dry season, the plume primarily passes westerly from Manaus, and $60 \%$ of the time it is modeled to pass over the site T3. The modeling, however informative, comes with some caveats. Trajectory modeling is based on mean wind fields and as such does not account for vertical and horizontal dispersion of pollutants by turbulent mixing. River breezes, effectively introducing overturning and mixing at the river margins, can occur at fine-enough scales that they are not captured by the trajectory modeling.

A Lagrangian design of the surface sites along the plume, including upwind, coupled to aircraft flights in transect to the plume during transport was a powerful and compelling feature of GoAmazon2014/5. The pollution plume was extensively characterized by flights of the G-159 Gulfstream I (G-1) aircraft of the Atmospheric Radiation Measurement (ARM) Aerial Facility (AAF) of the U.S. Department of Energy (DOE; Stokes and Schwartz 1994; Mather and Voyles 
2013; Schmid et al. 2014). Missions were flown in both the wet and dry seasons. The experiment took place continuously across 2 years from 1 January 2014 through 31 December 2015, and there were intensive operating periods (IOPs) during the wet and dry seasons of 2014 (IOP1 and IOP2, respectively). Research sites and instrumentation of GoAmazon2014/5 are presented in further detail in Martin et al. (2016). In the present account, the first general picture of GoAmazon2014/5 results is presented.

OBSERVATIONS. The organization of GoAmazon2014/5 results, as presented herein, follows the origins-to-effect sequence represented in the left panel of Fig. 1. In origin, there are natural and anthropogenic emissions of both gaseous compounds and aerosol particles (Martin et al. 2010a). In sequence, important chemical transformations occur for some of the gaseous compounds, ultimately affecting the aerosol particles because of gas-to-particle conversion processes (Martin et al. 2010b). These aerosol particles serve as cloud condensation nuclei $(\mathrm{CCN}$;
Poschl et al. 2010). The physicochemical properties of this CCN population differ significantly between background and polluted conditions (Andreae and Rosenfeld 2008). In net effect, cloud microphysics, droplet size distributions, droplet lifetime, and rainfall can be altered by this sequence of events (Rosenfeld et al. 2008). The large arrow in Fig. 1 represents the sweep of these species and associated processes through Manaus and then westward in the prevailing direction of the urban plume across the Rio Negro (Black River). Based on measurements obtained from an airborne platform, an informative, interesting, and compelling visualization is presented herein of the pollution plume in the wet season and some of its atmospheric effects over the Green Ocean.

The visualization from the G-1 aircraft of the downwind effects of urban air pollution based on the aircraft measurements is presented in Figs. 4-7. A revealing crosscut through the complex multidimensional datasets of position, time, and measurement type is presented in the following sections. The flight on 13 March 2014, a day of mostly sunny skies
IOP1

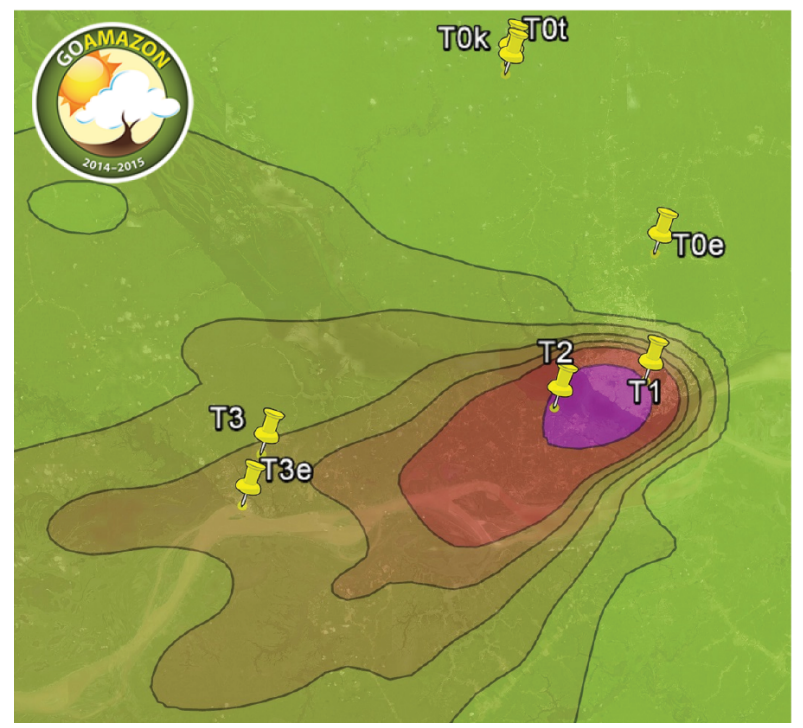

IOP2

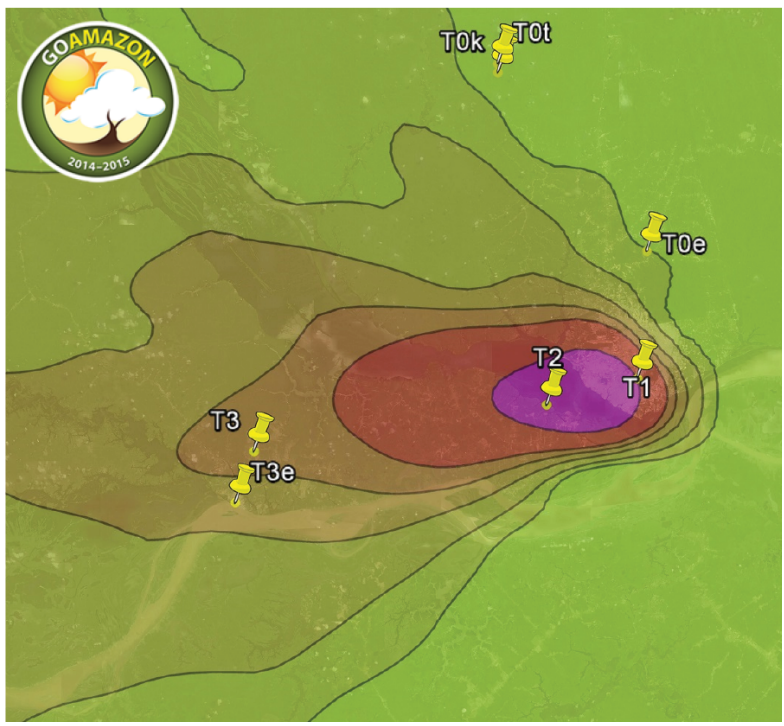

FIG. 2. Statistical composite of forward trajectories launched $500 \mathrm{~m}$ above site TI in Manaus at 0000, 0600, 1200 , and 1800 UTC for (left) the 59 days of IOPI (I Feb-3I Mar 20I4) and (right) the 60 days of IOP2 (I5 Aug-I5 Oct 2014). Easterlies associated with trade winds normally swept the urban pollution plume westward toward the downwind research sites. The intensity of the contour coloring represents the frequency for trajectories that passed nearby the latitude-longitude position represented by the map. Contours are drawn at $2 \%, 5 \%$, $10 \%, 15 \%, 20 \%$, and $40 \%$ frequency on a grid size of $0.1^{\circ} \times 0.1^{\circ}$. Yellow pins indicate the locations of some of the GoAmazon2014/5 research sites (cf. Fig. 3). These results are produced by the Meteorologia Aplicada a Sistemas de Tempo Regionais-Instituto de Astronomia, Geofísica e Ciências Atmosféricas (MASTER-IAG; www.master .iag.usp.br/) model using a combination of data assimilation from the Global Forecast System-National Centers for Environmental Prediction (GFS-NCEP; www.nco.ncep.noaa.gov/pmb/products/gfs $/$ ) at $0.5^{\circ}$ resolution and numerical modeling with Brazilian Regional Atmospheric Modeling System (BRAMS; http://brams.cptec.inpe .br/) at 2-km resolution of forward trajectories launched over Manaus (TI; Silva Dias et al. 2006; Freitas et al. 2009; all websites accessed 3 Jan 2016). 
and no precipitation along the flight path, serves as a reference.

As an example, the total particle concentrations measured by a condensation particle counter are represented in Fig. 4 for transect flights at 500 -m altitude in the late morning of 13 March. The concentration is plotted in blue in the altitude axis of Fig. 4a1. The dominance of the Manaus plume over background conditions is immediately apparent. Transect legs for this flight were separated by approximately $15 \mathrm{~min}$, representing about $1 \mathrm{~h}$ of flight time from Manaus to the T3 site. The time for the plume to

Fig. 3. The GoAmazon2014/5 experiment in pictures. (top left) The verdant Amazon rain forest forming a green ocean, as observed from the top of the research tower at T0k. (top right) Photo of G-I aircraft taken when flying in formation with the HighAltitude and Long-Range Research Aircraft (HALO) aircraft. Compared to the G-I that mostly sampled regionally around Manaus with a focus on the pollution plume, the HALO aircraft mostly observed the free troposphere across a larger part of the Amazon basin. Those observations are described in a complementary article by Wendisch et al. (2016). (middle) Yellow pins indicate the of GoAmazon2014/5 research sites in the environs of the city of Manaus $\left(-3.1^{\circ},-60.0^{\circ}\right)$ in the state of Amazonas in the country of Brazil. The ground sites include upwind locations (TOa, TOe, TOk, and TOt), source location (TI), and downwind locations (T2, T3, and T3u; Martin et al. 2016). Site T0a is the Amazonian Tall Tower Observatory (ATTO) described by Andreae et al. (2015). Manaus sits at the confluence of Rio Negro and Rio Solimões, where the named Rio Amazonas begins (Portuguese names). The inset shows the location of the experimental domain within South America. For prevailing winds, Manaus is on the order of $1,200 \mathrm{~km}$ from the Atlantic Ocean during the wet season and I,600 km during the dry season. (bottom left) Aerial view of the research containers at the T3 research site. This site was administered by the ARM Climate Research Facility, a user facility of the United States Department of Energy (Mather and Voyles 2013), in collaboration with Brazilian National Institute of Amazonian Research (INPA). (bottom right) Ground-level shot highlighting two of the radar systems at T3. 

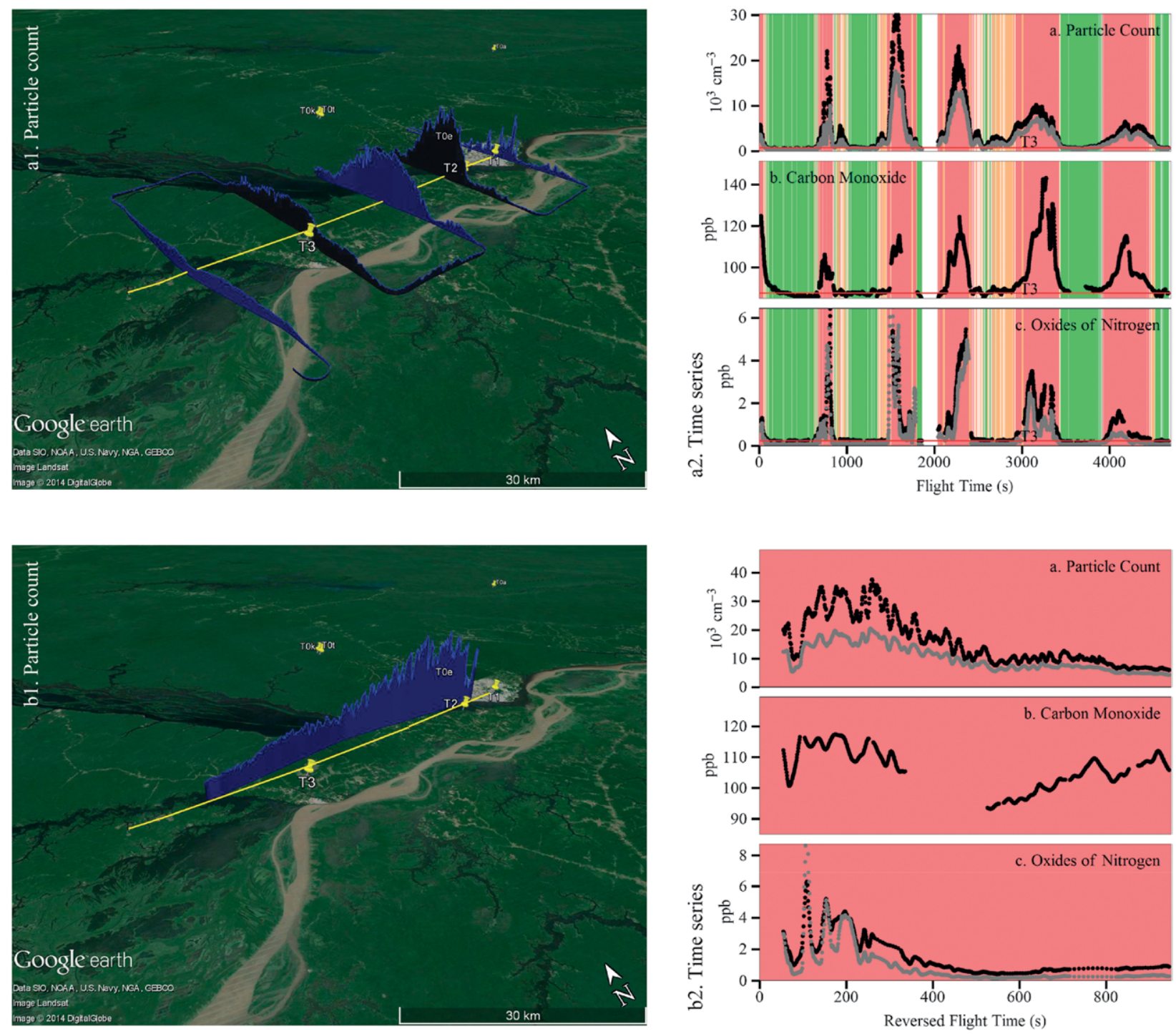

travel from Manaus to T3 on this day was longer than $3 \mathrm{~h}$ according to the trajectory modeling (yellow line). The implication is that the aircraft and the instrumentation on board sampled the plume much more rapidly than the plume itself was changing. To a first approximation, Fig. 4 thus serves as a freeze-frame visualization of the entire plume during the time of the aircraft flight.

Gaseous pollutants and chemistry. Several measurements characterizing the pollution plume are plotted in the bottom-left panel of Fig. 4 along the flight path of Fig. 4a1. Carbon monoxide (CO), produced during incomplete combustion in vehicles and power plants, and oxides of nitrogen $\left(\mathrm{NO}_{x}\right)$, associated with combustion with air as the oxidant, are also plotted in Fig. 4a2. $\mathrm{CO}, \mathrm{NO}_{x}$, ozone $\left(\mathrm{O}_{3}\right)$, and particulate matter (PM) are important markers of air quality (Unger
2012). $\mathrm{NO}_{x}$ is a reactive species, contributing to net ozone production in the plume. The plot shows that the $\mathrm{NO}_{x}$ concentration decreased along the plume. In addition to loss by entrainment and deposition, $\mathrm{NO}_{x}$ can be chemically transformed into $\mathrm{HNO}_{3}$ by reaction with $\mathrm{OH}$ and to organonitrates by reaction with photochemically produced organic radicals (Perring et al. 2013). By comparison, carbon monoxide can be regarded largely as chemically inert on the time scales of Fig. 4. Typically, CO concentration should decrease downwind because of dilution by mixing, entrainment, and other physical processes. For the shown flight data, the CO concentration actually increased by $20 \mathrm{ppb}$ with time, providing information about the time course of emissions in Manaus. Up to $5 \mathrm{ppb}$ CO is modeled as produced from photooxidation in the plume between Manaus and T3. The flight time of 3,000 s over T3 corresponded to 1055 local time (LT), 
4 FIG. 4. Visualization of the Manaus pollution plume. (left) The direction and extent of the plume observed in the Manaus environs by the G-I aircraft is represented by plotting particle number concentrations in the vertical axis. (right) Several tracers of the pollution plume, especially as related to air quality, are plotted. The abscissa represents position along the flight path shown in the left-hand plots. (al) Particle concentrations recorded by a condensation particle counter (CPC; TSI Model 3025A) on board the G-I aircraft on a flight track at $500 \mathrm{~m}$ above mean sea level (MSL) from 1415 to 1533 UTC 13 Mar 2014, corresponding to 1015-II33 LT. Local topography varies from 50 to $100 \mathrm{~m}$ MSL. The panel shows an image of the local land cover upon which relative particle concentrations along the flight track are plotted in the vertical axis in blue coloring. The flight track was transverse to the Manaus pollution plume. Yellow pins indicate the locations of some of the GoAmazon2014/5 research sites (cf. Fig. 3). The yellow line shows the simulated trajectory of an air parcel released over Manaus at $500 \mathrm{~m}$ MSL. (a2) Time series of concentrations of (top) particles, (middle) carbon monoxide, and (bottom) oxides of nitrogen along the flight track of (al). Time 0 corresponds to 1533 UTC. For particle concentrations, the black and gray traces correspond to particles of $3 \mathrm{~nm}$ and larger and $10 \mathrm{~nm}$ and larger, respectively, using two different condensation particle counters (TSI Models 3025A and 3010, respectively). For concentrations of oxides of nitrogen, the black and gray traces correspond to concentrations of $\mathrm{NO}_{2}$ and $\mathrm{NO}$, respectively. The red line represents concentrations recorded in background air masses during the flight and thus represents a baseline against which to measure the effects of pollution on species concentrations. The designation T3 at 3,088 s indicates the time point at which the G-I aircraft was located over the T3 research site. Background coloring designates that the G-I was passing through a background air mass (light green), a polluted air mass (light red), or an air mass having an undetermined pollution state (light orange). The classification algorithm took as input the concentrations of particles, carbon monoxide, and oxides of nitrogen. (bl) Particle concentrations recorded on the same flight as (al) at $500 \mathrm{~m}$ MSL but from 1539:00 to I554:00 UTC, corresponding Fig. 4. to II39-II54 LT. The flight track was longitudinal to the Manaus pollution plume. (b2) Time series of species concentrations along the flight track of (bl). Although the actual flight was upwind to visualize as downwind translation from Manaus, time is expressed in reverse flight time. Hence, time 0 corresponds to 1554 UTC. Trace coloring is as in (a2). Reported concentrations are normalized to STP $\left(10^{5} \mathrm{~Pa}, 273.15 \mathrm{~K}\right)$.

- Fig. 5. Concentrations of atmospheric gases along the transverse flight tracks of Figs. 4al and 4a2: (a) ozone, (b) isoprene, (c) ratio of oxidation products and isoprene, and (d) ratio of benzene and toluene. The datasets reveal the acceleration of the oxidant cycle inside compared to outside the plume downwind of Manaus (see main text). Isoprene oxidation products include methyl vinyl ketone, methacrolein, and hydroperoxides. Organic species were measured by proton transfer reaction mass spectrometry (PTR-MS). The background coloring to designate the pollution state of an air mass, the red line to designate baseline concentrations, and the label T3 are as discussed in Fig. $4 \mathrm{a} 2$.

which traces back to rush hour in Manaus at $0800 \mathrm{LT}$. The Manaus emissions of CO added to a background concentration of approximately $80 \mathrm{ppb}$ on this day. Given the estimated atmospheric lifetime of $\mathrm{CO}$ of greater than 1 month, the background concentration has contributions from anthropogenic and biogenic sources both inside and outside of the Amazon basin (Andreae et al. 2012).

In addition to the primary emissions (e.g., Fig. 4), the pollutants in the plume also have strong secondary effects. Results in Fig. 5 for this same late morning, fair weather flight on 13 March demonstrate an accelerated and transformed photochemical cycle. These changes can be attributed to a combination of strong solar irradiance at this equatorial latitude and high

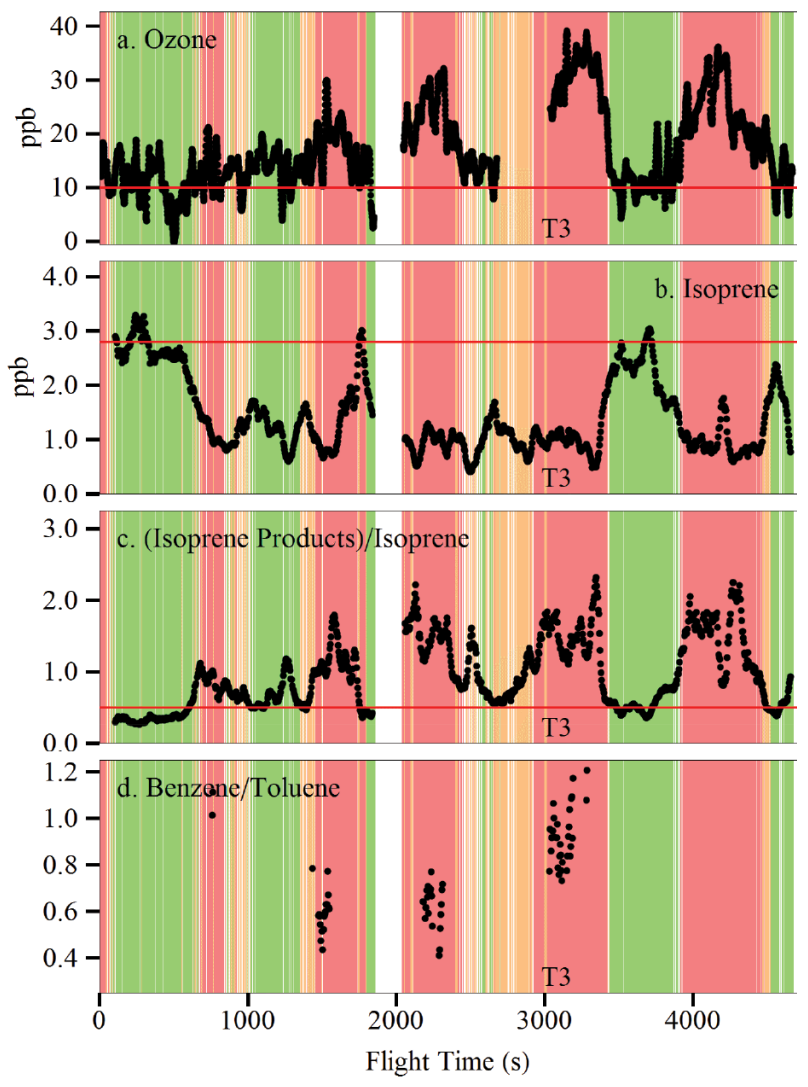

concentrations of $\mathrm{NO}_{x}$ within the plume. As a result, the production rate of ozone, a secondary species produced in situ in the atmosphere (Chameides et al. 
1988), increased, as seen in its progressive buildup in Fig. 5a for plume transects farther downwind of Manaus (see the sidebar "Ozone Production in Urban Pollution Plume").The red line represents the baseline concentrations measured when the aircraft was flying in the background atmosphere outside the plume. The concentrations of the other important atmospheric oxidant, the hydroxyl radical (also a secondary species; Valin et al. 2013), increased severalfold when measured at the $\mathrm{T} 3$ ground site during times when the Manaus plume intersected the site under sunny conditions (see the sidebar "Oxidant Cycle").

Further indicators of the accelerated oxidant cycle are the decreased BVOC concentrations measured inside relative to outside the plume (e.g., Fig. 5b). BVOCs are emitted by the forest, and their concentrations in the boundary layer are a blended effect of emissions rates, reactive loss in the atmosphere, dilution by vertical mixing, and deposition to the planetary surface. Elevated concentrations of hydroxyl radical and ozone increase reactive loss of BVOCs and thereby decrease BVOC concentrations. The effects of this accelerated loss are apparent in Fig. 5b. When the aircraft transected the plume, the concentration of isoprene, measured on board the aircraft by a proton transfer reaction mass spectrometer, was much lower. Similar results were observed for other BVOCs, such as $\alpha$-pinene (Fig. ES1; a supplement to this article is available online at http://dx.doi .org/I0.II75/BAMS-D-I5-00221.2). Corresponding to the loss of the parent species isoprene, its product species were produced. Figure $5 \mathrm{c}$ shows the buildup of the ratio of isoprene oxidation products to isoprene. The ratio increased from less than unity to more than 2 . The ratio increased because of the simultaneous increase in the concentrations of species

\section{OZONE PRODUCTION IN URBAN POLLUTION PLUME}

M odels are used to help understand the effects of human activities on the spatial and temporal variability of important and complex quantities. An example is described here for ozone. Ozone is a secondary trace gas produced by photochemical reactions of nitrogen oxides and volatile organic compounds emitted from anthropogenic and biogenic sources. Exposure to high concentrations of ozone has been shown to be hazardous for human health and cause plant damage. Relatively low ozone concentrations are maintained in the Amazon basin by photochemical production from biogenic emissions, although downward transport during convective events can lead to isolated and rapid increases in surface ozone concentrations. The rate of photochemical production is modulated by the presence of clouds that frequently occur. During the dry season, biomass burning releases additional precursor gases that further enhance ozone production. Ozone is removed from the atmosphere by dry deposition on plant surfaces. Daily maximum ozone concentrations are usually between 10 and $20 \mathrm{ppb}$ during the wet season under background conditions, but values as high as $100 \mathrm{ppb}$ have been observed during the dry season in the presence of biomass burning. Pollutants emitted from Manaus perturb the background atmosphere of the tropical rain forest and react with volatile organic compounds emitted from the forest. Figure SBI shows an example simulation from the Weather Research and Forecasting
(WRF)-Chem Model of ozone mixing ratios downwind of Manaus for 13 March 2014. Based on the G-I measurements, the observed plume centerline passed over the T2 and T3 sites on this day. Although the plume centerline of the model is north of the observed centerline location due to errors in the simulated wind direction, the concentrations are similar to the observations as shown in Fig. 5a. The model demonstrates that anthropogenic emissions influence chemical reactions over the rain forest far downwind of Manaus, such as depleting isoprene emitted by the forest. Modeling helps to better anticipate possible future impacts of climate change and population increases in the Amazon basin and other tropical regions of the world.

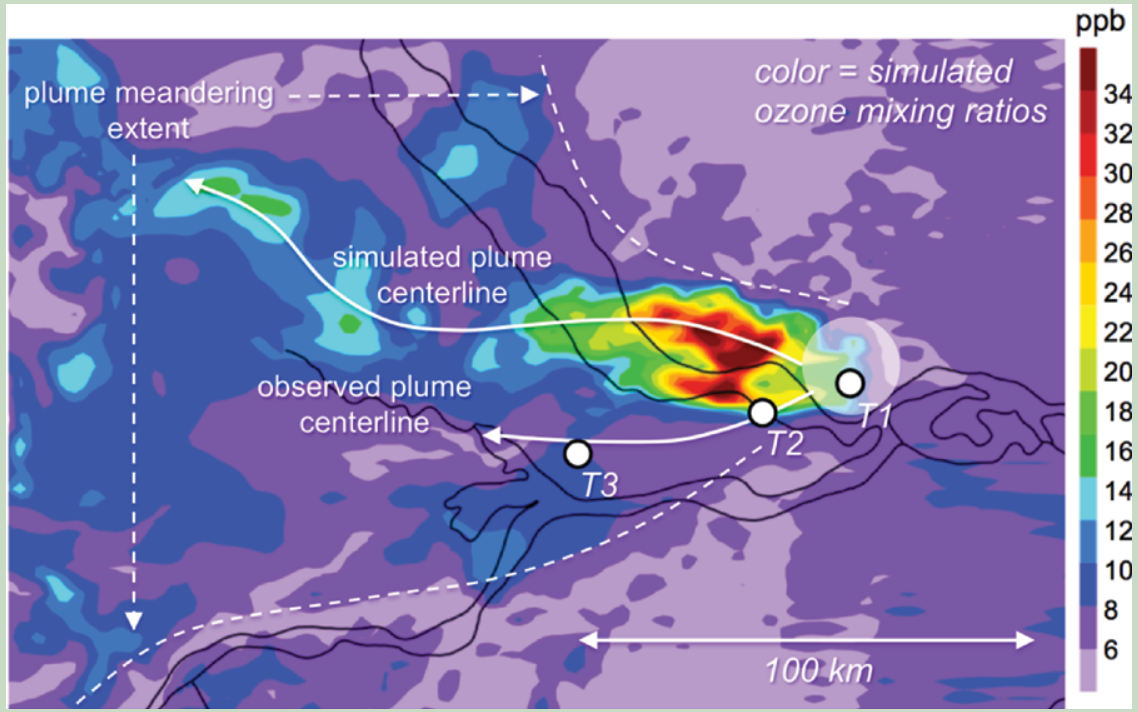

FIG. SBI. Modeling the urban pollution plume. 
produced by isoprene oxidation (i.e., methyl vinyl ketone and methacrolein) and decrease in isoprene itself (Fig. ES1). Benzene and toluene, which are anthropogenic emissions from Manaus, can provide a chemical clock of photochemical age because benzene reacts more slowly than toluene with $\mathrm{OH}$ radicals. As a result, the ratio increased downwind from Manaus (Fig. 5d). In short, with respect to photochemical aging of gaseous and particulate species by $\mathrm{OH}$ radical reaction, the overall changes in Fig. 5 demonstrate an acceleration of the oxidant cycle by a factor of severalfold during the time of the flight. One hour in the pollution plume can be considered equivalent, on a reaction basis, to several hours in background air on this day, and this phenomenon is referred to as acceleration of the oxidant cycle.

In addition to accelerating the oxidation cycle by increasing $\mathrm{OH}$ and $\mathrm{O}_{3}$, the plume also transformed it. Higher NO concentrations intercepted organic radical species and transformed them into different types of products than those that form under background conditions (Atkinson 1990; Atkinson and Arey 2003; Liu et al. 2013; Liu et al. 2016). Species such as organic hydroperoxides were replaced by species such as organonitrates, among others (Farmer et al. 2010). The organic PM in the plume had contributions both from the primary emissions of Manaus as well as from secondary processing tied to gas to particle partitioning in the accelerated chemistry of the plume. Although difficult to observe directly using the instrumentation on board the G-1, this suite of additional chemical changes was recorded by more extensive analytical instrumentation deployed at the ground sites (results not shown herein) (IsaacmanVanWertz et al. 2016).

Particulate matter number concentrations. The concentration of particles in the center of the plume approached $30,000 \mathrm{~cm}^{-3}$ [standard temperature and pressure (STP)], compared to less than $500 \mathrm{~cm}^{-3}$ under background conditions (Fig. 4a2, top row). The gray and black lines correspond to concentrations of particles having diameters greater than 3 and $10 \mathrm{~nm}$, respectively, denoted as $N_{>3}$ and $N_{>10}$, hereafter. The difference between $N_{>3}$ and $N_{>10}$ shows the importance of nanoparticles in the Manaus plume, believed to be largely derived from new particle production associated with combustion emissions. The difference between $N_{>3}$ and $N_{>10}$ became negligible sufficiently downwind, indicating the absence of the smallest particles by that point. The decrease in concentration of both $N_{>3}$ and $N_{>10}$ with flight time, representing farther downwind from Manaus, arose

\section{OXIDANT CYCLE}

7 he lifetime of many species in the atmosphere depends on the reaction rate with hydroxyl radical $(\mathrm{OH})$. Elevated $\mathrm{NO}_{x}$ concentrations in the pollution plume of Manaus can increase the rate of $\mathrm{OH}$ radical production and hence the steady-state concentration of $\mathrm{OH}$ radicals. As a result, the oxidation cycle can become accelerated, meaning that the concentrations of parent species decrease and the concentrations of product species increase because of the higher $\mathrm{OH}$ concentrations. One specific example highlighted in this article is the decreased concentrations of isoprene and the increased concentrations of its daughter species methyl vinyl ketone and methacrolein (Figs. 5b,c). Direct measurements of $\mathrm{OH}$ radical concentrations were also made at the $\mathrm{T} 3$ ground site, and the accelerating effect of the pollution plume can be directly resolved. As seen in Fig. SB2, on 14 March 2014, there was an abrupt shift at 1600 UTC in particle counts (scaled from 0 to $12,000 \mathrm{~cm}^{-3}$ ) and ozone concentrations (scaled from 0 to $60 \mathrm{ppb}$ ). This shift corresponded to a change in local winds from easterlies, which carried the Manaus plume, to southerlies, which transported background air. Because the hydroxyl radical has a lifetime of less than I s, the measured $\mathrm{OH}$ concentrations are specifically representative of each air mass. For similar solar irradiation, the hydroxyl radical concentration increased by a factor of more than 3 for polluted compared to background air.

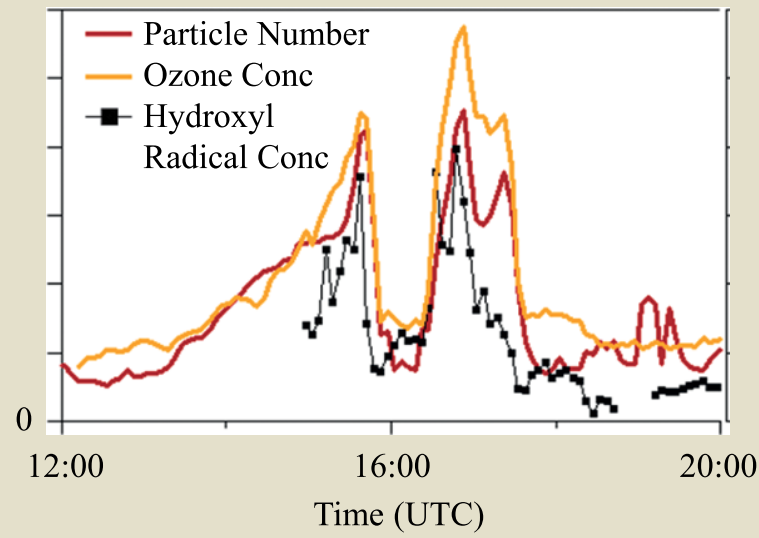

FIG. SB2. The accelerated oxidant cycle.

from a combination of coagulation, dilution from vertical entrainment of clean air, dilution from horizontal dispersion, and dry deposition. There was no precipitation along the flight path on this day, which otherwise can decrease particle concentration by wet deposition and deep convection.

The transects across the plume were complemented in a moment of real-time in-flight excitement when the flight scientist identified the location of the plume and then directed the aircraft to follow a flight 
course directly up the central axis of the plume. The results are plotted in Figs. $4 \mathrm{~b} 1$ and $4 \mathrm{~b} 2$. The interpretation of these panels must be considered with some care because the flight leg and the central axis of the plume are somewhat askew of one another, and the concept of a central axis for the plume is somewhat

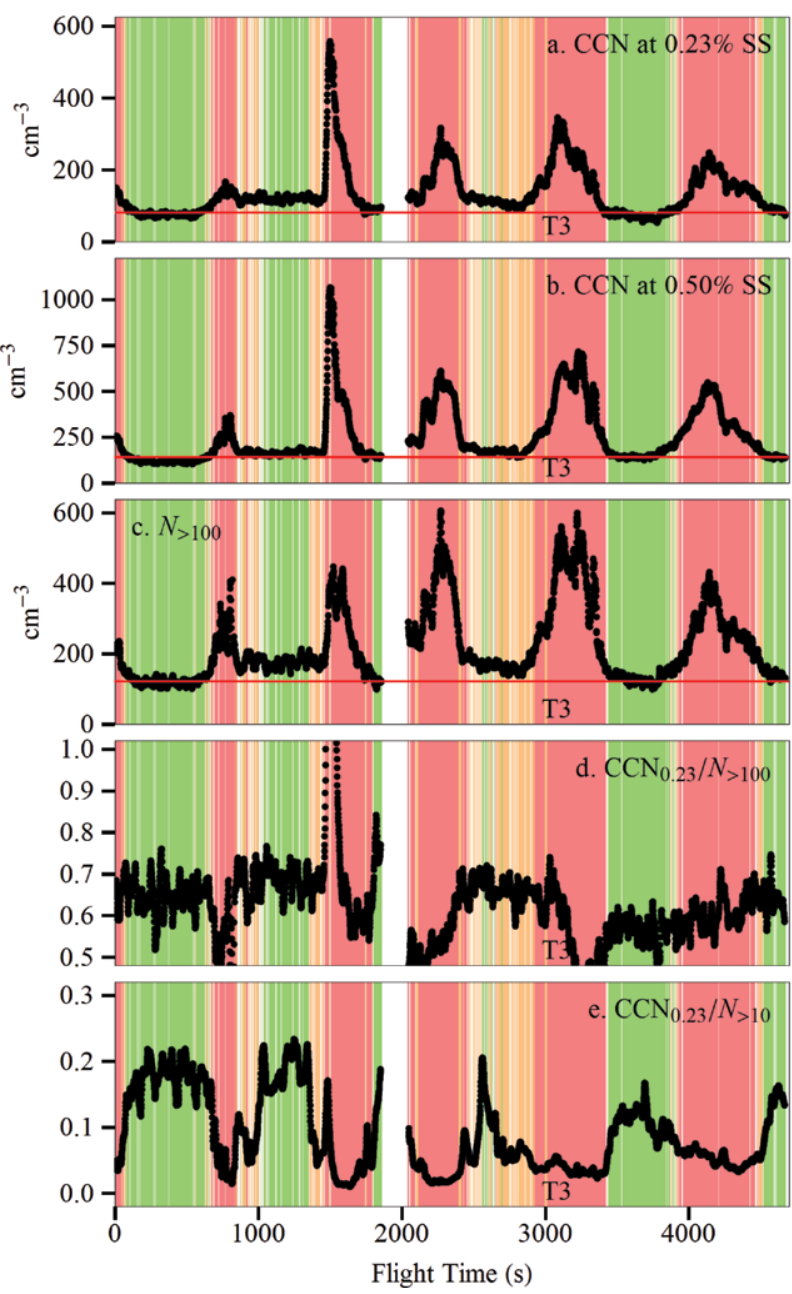

Fig. 6. Properties of $\mathrm{CCN}$ along the transverse flight corresponding to Fig. $4 \mathrm{al}$. The datasets show that the cloud-forming characteristics of the atmospheric PM were altered by the pollution plume. (a) $C C N$ concentrations measured at $0.23 \%$ supersaturation. (b) $\mathrm{CCN}$ concentrations measured at $0.5 \%$ supersaturation. (c) Total particle concentration of diameters of $100 \mathrm{~nm}$ and larger. (d) Fraction of $\mathrm{CCN}$-active particles calculated as the ratio of $\mathrm{CCN}$ concentrations at $0.23 \%$ to total particle concentrations of diameters of $100 \mathrm{~nm}$ and larger. (e) Fraction of $\mathrm{CCN}$-active particles calculated as the ratio of $\mathrm{CCN}$ concentrations at $0.23 \%$ to total particle concentrations of diameters of $10 \mathrm{~nm}$ and larger. The background coloring to designate the pollution state of an air mass, the red line to designate baseline concentrations, and the label T3 are as discussed in Fig. 4 a2. fictitious in the dynamical setting of winds, entrainment, and dispersion. Even so, the visualization in Fig. $4 \mathrm{~b} 1$ of the axial flight clearly conveys the idea of plume extending from Manaus, in which particle number concentrations decrease with distance. The top row of Fig. $4 \mathrm{~b} 2$ shows this decrease more quantitatively, as concentrations decreased from 35,000 to $10,000 \mathrm{~cm}^{-3}$ in the transit from Manaus to T3 during this flight.

Although the data in Fig. 4b2 reflect a clear trend in particle concentrations, undulations on the order of $\pm 20 \%$ are also apparent. These undulations can arise from a combination of processes. Early in the plume, heterogeneous emissions throughout Manaus from specific power plants and industrial areas contribute to variability of species concentrations in the plume. Later in the plume, differing amounts of vertical entrainment from the overlying free troposphere, a stochastically governed process, have taken place, and this entrained air has lower concentrations of the pollutants. A comparison to the datasets for $\mathrm{CO}$ and $\mathrm{NO}_{x}$ in the middle and bottom rows of Fig. $4 \mathrm{~b} 2$ provides some further insight into the relative contribution of these processes. Early in the plume, $\mathrm{CO}$ concentrations had less variability, suggesting that nonpoints sources, such as the transportation fleet of Manaus, represented the dominant source of this pollutant. By comparison, $\mathrm{NO}_{x}$ concentrations had relatively high variability, suggesting that point sources, such as power plants, strongly contributed to the concentrations of this pollutant. The particle count had tendencies of both, suggesting that both the transportation fleet (which has many diesel trucks to accompany the activities of the factories associated with the free-trade zone) and power plants had significant particle emissions. At later times (500-900 s, Fig. 4b2, nearby T3), undulations remain apparent in the measurements, despite the mixing tendencies associated with dilution, entrainment, and other aspects of turbulence, such as large eddies. The implication is that on this day specific lines of pollution within the plume maintained their integrity to a certain extent over the distance from Manaus to T3, implying that horizontal dispersion was rather weak and air parcels underwent quasi-Lagrangian transport from emission to observation, at least on this fair-weather day. Another observation is that the $\mathrm{CO}$ and $\mathrm{NO}_{x}$ concentrations at $800 \mathrm{~s}$ in Fig. 4 b2 are lower than their respective maximum values at $3,000 \mathrm{~s}$ in Fig. 4a2. Askewness between the flight path and the central axis of the plume can explain this observation, meaning that at $800 \mathrm{~s}$ the flight path was sampling the shoulder rather than the central values of the plume. 
Cloud condensation nuclei. The cloud-forming characteristics of the atmospheric PM were also altered by the pollution plume. For the flight on $13 \mathrm{March}$, the concentrations of particles activating as cloud droplets were 80 and $130 \mathrm{~cm}^{-3}$ outside the plume for supersaturations of $0.23 \%$ and $0.50 \%$, respectively (labeled $\mathrm{CCN}_{0.23}$ and $\mathrm{CCN}_{0.50}$; Figs. 6a,b). These supersaturations are typically achieved as maximum in-cloud supersaturations across the range from moderate to strong convection. By comparison, $\mathrm{CCN}_{0.23}$ and $\mathrm{CCN}_{0.50}$ shifted to values greater than 300 and $600 \mathrm{~cm}^{-3}$, respectively, in the central region of the pollution plume. Cloud microphysics is most sensitive to changes in CCN number concentrations from 100 to $1,000 \mathrm{~cm}^{-3}$, above which saturation effects occur (Reutter et al. 2009).

The increased CCN concentrations associated with the pollution plume can be partially attributed to changes in particle size (i.e., physics) as well as changes in intrinsic $\mathrm{CCN}$ activity (i.e., chemistry). The particles freshly emitted in Manaus, mostly smaller than $50 \mathrm{~nm}$ and having a high soot content, were both too small and too hydrophobic to serve favorably as CCN. Downwind, the particle number concentration decreased, in part because of nanoparticle coagulation, as discussed for Fig. 4 . Coagulation, as well as condensation of gases onto preexisting particles, increased the population of particles $100 \mathrm{~nm}$ and larger. Large particles tend to activate as $\mathrm{CCN}$ even at low supersaturations. Condensing gases are also produced more rapidly in the accelerated oxidant cycle of the pollution plume. The condensing gases include relatively hygroscopic species, such as carboxylic acids, alcohols, hydroperoxides, or sulfuric acid, resulting in particles of higher intrinsic $\mathrm{CCN}$ activity when condensational growth occurs. The CCN concentration thus progressively increased downwind of Manaus, both because of physics (i.e., mode diameter shifted to larger sizes) and chemistry (i.e., more hygroscopic constituents).

The effects of the plume on the downwind CCN concentrations are shown in Figs. 6c, 6d, and 6e for the flight of 13 March. The number concentration measured by the Passive Cavity Aerosol Spectrometer Probe (PCASP) instrument, sensitive to particle diameters of $100 \mathrm{~nm}$ and larger $N_{>100}$, steadily increased farther downwind within the plume (Fig. 6c), even as total particle number concentrations $N_{>3}$ and $N_{>10}$ decreased (Fig. 4a2, top row) indicating a shift of the particle population to a larger mode diameter. Because of the large diameters, most of these particles activated at $0.23 \%$ supersaturation, as reflected in the ratio of $\mathrm{CCN}_{0.23} / N_{>100}$ in Fig. 6d, which mostly varied from 0.5 to 0.8 for this flight. Even so, these $\mathrm{CCN}$-active particles remained a small fraction of the total particle population $\left(\mathrm{CCN}_{0.23} / N_{>10}\right.$; Fig. 6e). This ratio was nearly zero in the plume and about 0.2 for background conditions. The ratio $\mathrm{CCN}_{0.23} /$ $N_{>100}$ was typically lower inside the pollution plume. A shift in the relative size distribution of particles of
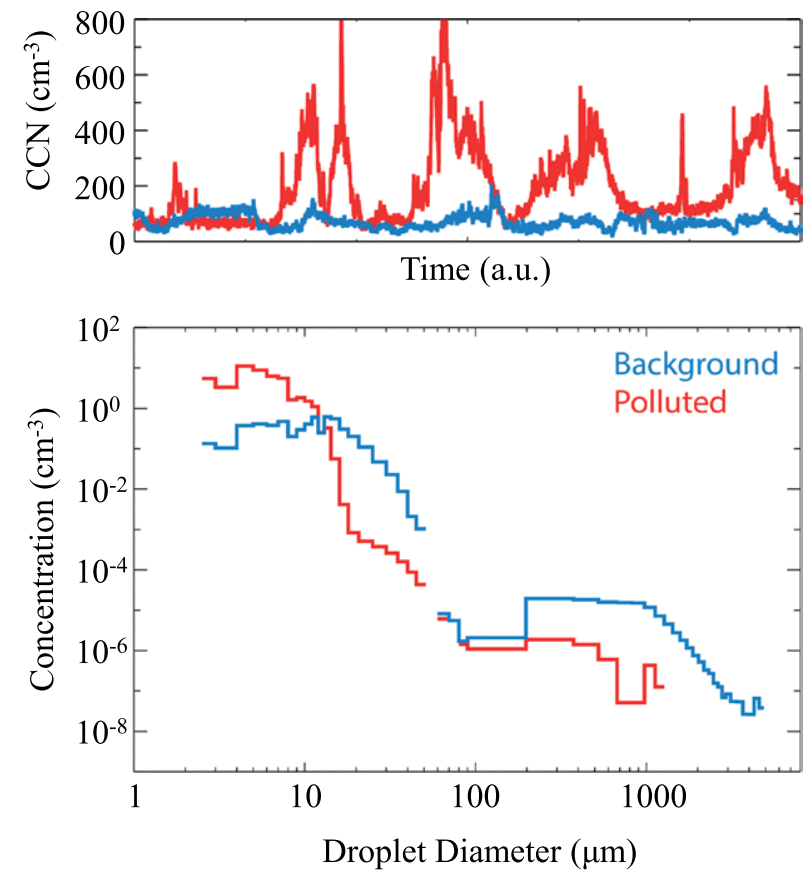

FIG. 7. Droplet size distributions of clouds under polluted and background conditions. The microphysical cloud properties in the regions affected by the Manaus plume are significantly different. (top) CCN concentrations at $0.35 \%$ supersaturation along a flight track on 19 Mar 2014 that passed through clouds under background conditions (blue) and along a flight track on 21 Mar 2014 that transected the Manaus pollution plume several times, while passing through clouds (red). Time on the abscissa runs from 1700 to 1800 UTC 2I Mar (polluted) and from 1440 to 1520 UTC 19 Mar (background) (bottom). Droplet size distributions for clouds during the polluted and background conditions represented by the top panel. The ordinate represents the differential concentration divided by the differential change in $\log _{10}$ (diameter). The distributions were prepared by concatenating the data recorded by the Cloud Droplet Probe (CDP), the Two-Dimensional Stereo Probe (2DS), and the High Volume Precipitation Spectrometer, version 3 (HVPS3). CDP data were used for sizes $<20.0 \mu \mathrm{m}$; 2DS and CDP data were averaged for sizes 20.0-50.0 $\mu \mathrm{m}$; 2DS data were used for sizes 50.0-100.0 $\mu \mathrm{m}$; and HVPS data were used for sizes $>100 \mu \mathrm{m}$. For the polluted case, data were filtered to include measurements having $C C N$ concentrations of $300 \mathrm{~cm}^{-3}$ and greater so as to consider only clouds inside the Manaus plume. 
diameters $100 \mathrm{~nm}$ and larger (i.e., to a smaller mode diameter) and a decrease in their hygroscopicity, both of which are associated with dominance of small hygroscopic particles in the plume, are both factors that can explain the decrease in $\mathrm{CCN}_{0.23} / N_{>100}$.

To a limited extent, the pollution plume also changed the thermodynamic context of cloud
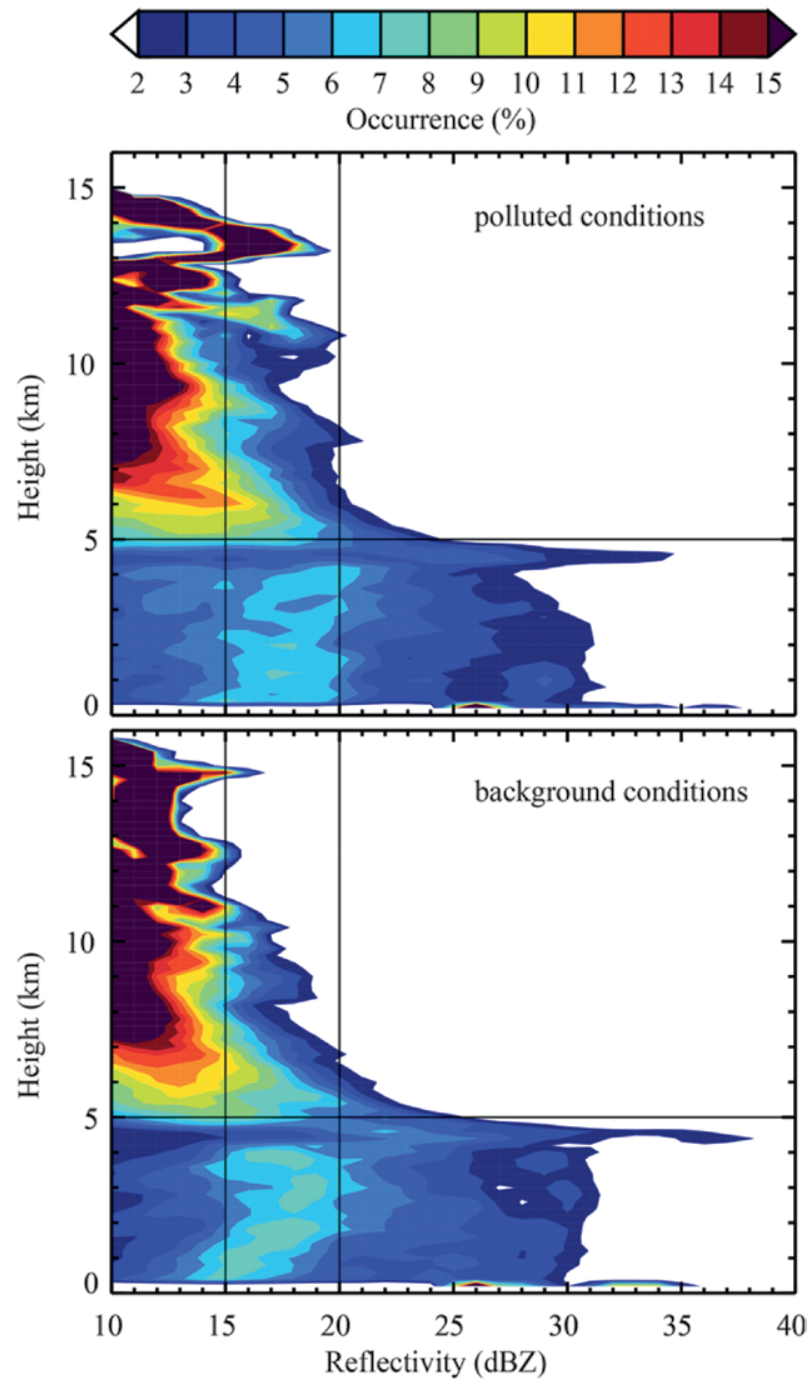

Fig. 8. Vertical distributions of the frequency radar reflectivity over site $\mathrm{T} 3$ during IOPI in the wet season. In statistical aggregate, the pollution plume downwind of Manaus appears to alter cloud properties. These plots are commonly referred to as a contoured frequency by altitude diagram CFAD, as introduced by Yuter and Houze (1995). Data are segregated by (top) polluted and (bottom) background conditions. Lines accompany the description in the text to demarcate a height of $5 \mathrm{~km}$ (horizontal line) and a reflectivity range of 15-20 dBZ (vertical lines). The data were collected in a vertical-pointing strategy by a dual-polarization, $X$-band scanning radar (Machado et al. 2014). formation in important ways. The PM observed during background conditions for this flight had a high single-scattering albedo of 0.95 or larger but blackened considerably in the plume, approaching a single-scattering albedo of 0.75 or less in the center of the plume (Fig. ES2). Light absorption causes a redistribution of energy in the atmospheric column, having a general tendency to increase atmospheric stability, decrease entrainment of overlying clean air, and weaken the environment for development of shallow clouds (Jacobson 2001).

Cloud properties. In light of changes both in $\mathrm{CCN}$ concentrations and possibly increased atmospheric stability at times because of absorption by black carbon, cloud properties in regions affected by the Manaus plume can be anticipated to change significantly. Even so, predictions of detailed effects on cloud formation are challenging because of myriad interacting factors, including but not limited to CCN concentrations, updraft velocity, temperature, and humidity (Andreae and Rosenfeld 2008). The observations made in GoAmazon2014/5, however, provide both qualitative descriptions and quantitative constraints of the effects of the pollution plume on cloud properties.

As an example, the droplet size distribution, meaning the probability density function of number concentration with diameter, is one important cloud property, affecting both cloud albedo as well as the tendency to convert from a nonprecipitating to precipitating state. Droplet size distributions were recorded when the aircraft passed through shallow cumulus clouds. The main reference day of $13 \mathrm{March}$ presented herein had mostly sunny skies, and the aircraft passed through hardly any clouds. Instead, datasets from 19 and $21 \mathrm{March}$, corresponding to the same latitude-longitude box downwind of Manaus and about the same altitude (600 m MSL), just above cloud base, were used in the analysis. The meteorological conditions such as temperature, relative humidity, and cloud vertical velocity were also similar for the two datasets. On 21 March, the Manaus pollution plume blanketed the selected latitude-longitude box. On 19 March, the Manaus pollution plume was outside this box. On both days, the flights passed through shallow cumulus clouds.

The CCN concentrations observed on 19 (background conditions; blue) and 21 March (polluted conditions; red) are shown in the top panel of Fig. 7 for $0.35 \%$ supersaturation. Under background conditions, $\mathrm{CCN}_{0.35}$ was approximately $100 \mathrm{~cm}^{-3}$ for both flights. It increased to $400-800 \mathrm{~cm}^{-3}$ inside the plume for the flight on 21 March. These observations are 
similar to those previously described for the main reference day of $13 \mathrm{March}$ (cf. Fig. 6). The bottom panel of Fig. 7 shows the size distributions, spanning droplets to raindrops, measured for the clouds under polluted and background conditions. The distributions differed considerably. Under polluted conditions, the droplet size distribution shifted to significantly smaller diameters, as explained by the increased CCN concentration. The dispersion of the distribution also decreased. The concentration of small droplets $(<10 \mu \mathrm{m})$ increased by up to two orders of magnitude in the polluted clouds. Raindrop concentrations $(>100 \mu \mathrm{m})$ correspondingly decreased significantly. Even so, caveats to keep in mind are that cloud formation mechanisms could differ between the days, and possible meteorological effects cannot be disentangled beyond doubt from possible effects of pollution. These caveats notwithstanding, the comparison between shallow cumulus clouds on these days is as reasonably similar as possible. In a broader statistical evaluation of clouds inside and outside the plume in the wet season, Cecchini et al. (2016) report similar findings. The differing size distributions suggest that the Manaus pollution plume has the general effect of slowing collision-coalescence processes of shallow cumulus clouds, thereby reducing droplet sizes and delaying or suppressing the formation of raindrops.

Precipitation. Differences in the droplet size distributions under polluted conditions compared to background conditions can influence the timing, amount, and intensity of rainfall, at least for some thermodynamic settings. Gonçalves et al. (2015) used observational evidence over the Manaus region to connect increased ice content, rain cells, and ultimately precipitation to elevated concentrations of atmospheric particles derived from biomass burning.
The smaller mode diameters of the droplet size distributions during cloud development under polluted conditions can suppress early stage precipitation within warm regions of the clouds. Liquid particles can rise to higher altitudes where freezing occurs, which is typically above $5 \mathrm{~km}$ over the Amazon. The latent heat of fusion promotes stronger updrafts and the growth of large ice particles, eventually leading to enhanced rainfall. This aerosol-cloud-precipitation mechanism is important in many environments (Khain et al. 2005; Rangno and Hobbs 2005; Rosenfeld et al. 2008; Fan et al. 2012).

As an illustration of these topics, Fig. 8 shows vertical distributions for the frequency of occurrence of radar reflectivity, commonly referred to as a contoured frequency by altitude diagram (CFAD). The data were collected at T3 during the wet season using a dual-polarization, X-band scanning radar in a vertical pointing strategy. Warmer colors represent a higher frequency of occurrence at a particular altitude, and the sum of occurrence at each height equals $100 \%$. The top and bottom panels represent data aggregated into polluted and 
background conditions, respectively. The two datasets respectively aggregate 1,680 and 881 observations of $10 \mathrm{~min}$ each. The polluted or background classification is based on a conglomeration of physical and chemical measurements at $\mathrm{T} 3$, such as particle number, $\mathrm{CCN}$, and $\mathrm{NO}_{\mathrm{x}}$ concentrations. Although environmental controls on cloud development are complex, even more so for a single cloud, broad aggregation over an extended dataset of many clouds and many days has the possibility to make a statistical comment regarding factors of influence, such as polluted compared to background conditions, on the effects of the Manaus plume on cloud development in the wet season.

In this regard, the CFAD analysis represented in Fig. 8 illustrates altered cloud properties associated with the pollution plume of Manaus in the wet season. The horizontal line at $5 \mathrm{~km}$ represents the typical height of the melting layer over the Amazon, below which warm rain processes are normally active. The vertical lines draw attention to a window of 15-20 dBZ in radar reflectivity. Clouds both above and below the melting layer are associated with a wider spread in reflectivity for polluted compared to background conditions. Below the melting layer, the wide spread in reflectivity suggests larger rainfall rates, larger mean drop sizes, or both. Above the melting layer, the high-end tail of the wide spread in reflectivity suggests that graupel and other mixedphase hydrometeors are larger, more numerous, or both under polluted conditions. The aforementioned aerosol-cloud-precipitation mechanism can explain the enhanced ice content under polluted conditions.

Given the myriad influences on rainfall occurrence and intensity, the most challenging analysis is to investigate the possible effect of the Manaus pollution plume on these outcomes. Disdrometer measurements at the T3 site are shown in Fig. 9. The rain rate and the mean mass-weighted diameter of the falling hydrometeors are measured. Figure 9 segregates the data for polluted and background conditions. The mean diameters of the two populations are not statistically different $(1.5 \mathrm{~mm})$, and the mean rain rates are not too different $\left(6.4\right.$ and $7.5 \mathrm{~mm} \mathrm{~h}^{-1}$ for background and polluted conditions, respectively). For most cases then, the overall precipitation distributions are not significantly different. A focus on strong rain rates, however, modifies the interpretation. For rain rates larger than $20 \mathrm{~mm} \mathrm{~h}^{-1}$ that denote deep convection, the mean diameter is larger for polluted conditions. The positive skewness representing the tail to larger diameters in the droplet distribution for the polluted compared to background conditions is statistically significant by the Student's $t$ test with greater than 95\% confidence. The implication appears to be that in the mixture of influences that affect rainfall occurrence and intensity at times, pollution can play a role in shifting the kinematic and microphysical growth processes. At those times, the shift to larger rain drops is consistent with the aerosol-cloud-precipitation mechanism of invigoration (May et al. 2011).

FINAL WORDS. In closing, just before the dawn of World War I, the Roosevelt-Rondon Scientific Expedition of 1913-14 took place up a deep tributary in southwestern Amazonia, and Theodore Roosevelt (President, United States, 1901-09) published thereafter Through the Brazilian Wilderness. In reference to the forest, he states that "decades will pass before it vanishes," (Roosevelt 1914, 333-334) by which he meant logging and other forms of development. In the most recent 10 years, a little over $2 \%$ of the forest has vanished. Tellingly, in 2015, acrid and thick smoke formed a pall across Manaus more often than not through October and November of the late dry season. Lifetime residents recall no other year as such. Although an El Niño year has been brought up as explanation, many El Niño years have come in the past without these fires, and in fact the quantitative incidence of fires in and around Manaus has increased steadily over the past 10 years at an annual average growth rate of $20 \%$. Possibly, 2015 is a harbinger of future years and could mark a major change in terms of fire location from the historical arc of deforestation along the southern margins of the Amazon forest and now into the central Amazon basin as well.

The results of GoAmazon2014/5 are improving understanding of the scientific factors affecting air quality, weather, terrestrial ecosystems, and climate in the basin, especially as related to susceptibility to specific human factors. A positive legacy will be that future regional development will take into account what is learned from GoAmazon2014/5 when making choices about future transportation networks, energy matrices, land-use changes, and other pertinent factors. In addition to the recent technical introduction by Martin et al. (2016) to the GoAmazon2014/5 experiment, several overview papers focused on more specific topics are forthcoming in Atmospheric Chemistry and Physics to summarize and synthesize findings concerning the aerosol life cycle, the cloud life cycle, and cloud-aerosol-precipitation interactions, in particular their functioning under background conditions compared to times of direct human influence. 
ACKNOWLEDGMENTS. Institutional support was provided by the Central Office of the Large-Scale Biosphere Atmosphere Experiment in Amazonia (LBA), the National Institute of Amazonian Research (INPA), the National Institute for Space Research (INPE), Amazonas State University (UEA), and the Brazilian Space Agency (AEB). The Office of Biological and Environmental Research of the Office of Science of the United States Department of Energy is acknowledged for funding (Grant SC0006680), specifically the Atmospheric Radiation Measurement (ARM) Climate Research Facility, the Atmospheric System Research (ASR) Program, the Terrestrial Ecosystem Sciences (TES) Program, the Regional and Global Climate Modeling (RGCM) Program, and the Environmental Molecular Sciences Laboratory (EMSL). Further funding was provided by the Amazonas State Research Foundation (FAPEAM), the São Paulo State Research Foundation (FAPESP), the Brazil Scientific Mobility Program (CsF/ CAPES), the United States National Science Foundation (NSF), the German Max Planck Society (MPG), the German Research Foundation (DFG), and the German Aerospace Center (DLR). The work was conducted under scientific licenses 001030/2012-4, 001262/2012-2, and 00254/2013-9 of the Brazilian National Council for Scientific and Technological Development (CNPq). We thank Karla M. Longo for her leadership related to the G-1 aircraft as part of GoAmazon2014/5.

\section{REFERENCES}

Andreae, M. O., 2007: Aerosols before pollution. Science, 315, 50-51, doi:10.1126/science.1136529.

— tion interactions. Part 1. The nature and sources of cloud-active aerosols. Earth Sci. Rev., 89, 13-41, doi:10.1016/j.earscirev.2008.03.001.

,-- , P. Artaxo, A. A. Costa, G. P. Frank, K. M. Longo, and M. A. F. Silva-Dias, 2004: Smoking rain clouds over the Amazon. Science, 303, 1337-1342, doi:10.1126/science.1092779.

— , and Coauthors, 2012: Carbon monoxide and related trace gases and aerosols over the Amazon basin during the wet and dry seasons. Atmos. Chem. Phys., 12, 6041-6065, doi:10.5194/acp-12-6041-2012. — , and Coauthors, 2015: The Amazon Tall Tower Observatory (ATTO): Overview of pilot measurements on ecosystem ecology, meteorology, trace gases, and aerosols. Atmos. Chem. Phys., 15, $10723-$ 10776, doi:10.5194/acp-15-10723-2015.

Artaxo, P., and Coauthors, 2002: Physical and chemical properties of aerosols in the wet and dry seasons in Rondônia, Amazonia. J. Geophys. Res., 107, 1-14, doi:10.1029/2001JD000666.
—_, and Coauthors, 2013: Atmospheric aerosols in Amazonia and land use change: From natural biogenic to biomass burning conditions. Faraday Discuss., 165, 203-235, doi:10.1039/c3fd00052d.

Atkinson, R., 1990: Gas-phase tropospheric chemistry of organic compounds: A review. Atmos. Environ., 24, 1-41, doi:10.1016/0960-1686(90)90438-S.

— , and J. Arey, 2003: Gas-phase tropospheric chemistry of biogenic volatile organic compounds: A review. Atmos. Environ., 37, 197-219, doi:10.1016 /S1352-2310(03)00391-1.

Bateman, A. P., and Coauthors, 2016: Sub-micrometre particulate matter is primarily in liquid form over Amazon rainforest. Nat. Geosci., 9, 34-37, doi:10.1038/ngeo2599.

Cecchini, M. A., and Coauthors, 2016: Impacts of the Manaus pollution plume on the microphysical properties of Amazonian warm-phase clouds in the wet season. Atmos. Chem. Phys., 16, 7029-7041, doi:10.5194/acp-16-7029-2016.

Chameides, W., R. Lindsay, J. Richardson, and C. Kiang, 1988: The role of biogenic hydrocarbons in urban photochemical smog: Atlanta as a case study. Science, 241, 1473-1475, doi:10.1126/science .3420404.

Davidson, E. A., and Coauthors, 2012: The Amazon basin in transition. Nature, 481, 321-328, doi:10.1038 /nature10717.

Fan, J., D. Rosenfeld, Y. Ding, L. R. Leung, and Z. Li, 2012: Potential aerosol indirect effects on atmospheric circulation and radiative forcing through deep convection. Geophys. Res. Lett., 39, L09806, doi:10.1029/2012GL051851.

Farmer, D. K., A. Matsunaga, K. S. Docherty, J. D. Surratt, J. H. Seinfeld, P. J. Ziemann, and J. L. Jimenez, 2010: Response of an aerosol mass spectrometer to organonitrates and organosulfates and implications for atmospheric chemistry. Proc. Natl. Acad., 107, 6670-6675, doi:10.1073/pnas.0912340107.

Freitas, S. R., and Coauthors, 2009: The Coupled Aerosol and Tracer Transport model to the Brazilian developments on the Regional Atmospheric Modeling System (CATT-BRAMS) - Part 1: Model description and evaluation. Atmos. Chem. Phys., 9, 2843-2861, doi:10.5194/acp-9-2843-2009.

Garstang, M., and Coauthors, 1990: The Amazon Boundary-Layer Experiment (ABLE 2B): A meteorological perspective. Bull. Amer. Meteor. Soc., 71, 19-32, doi:10.1175/1520-0477(1990)071<0019: TABLEA $>2.0 . \mathrm{CO} ; 2$.

Gonçalves, W. A., L. A. T. Machado, and P. E. Kirstetter, 2015: Influence of biomass aerosol on precipitation over the central Amazon: An observational study. 
Atmos. Chem. Phys., 15, 6789-6800, doi:10.5194 /acp-15-6789-2015.

Grandin, G., 2009: Fordlandia: The Rise and Fall of Henry Ford's Forgotten Jungle City. Metropolitan Books, 416 pp.

Isaacman-VanWertz, G., and Coauthors, 2016: Environ. Sci. Technol., 50, 9952-9962, doi:10.1021/acs. est.6b01674.

Jacobson, M. Z., 2001: Strong radiative heating due to the mixing state of black carbon in atmospheric aerosols. Nature, 409, 695-697, doi:10.1038/35055518.

Keller, M., M. Bustamante, J. Gash, and P. Dias, Eds., 2009: Amazonia and Global Change. Geophys. Monogr., Vol. 186, Amer. Geophys. Union, 565 pp.

Khain, A., D. Rosenfeld, and A. Pokrovsky, 2005: Aerosol impact on the dynamics and microphysics of deep convective clouds. Quart. J. Roy. Meteor. Soc., 131, 2639-2663, doi:10.1256/qj.04.62.

Kuhn, U., and Coauthors, 2010: Impact of Manaus city on the Amazon Green Ocean atmosphere: Ozone production, precursor sensitivity and aerosol load. Atmos. Chem. Phys., 10, 9251-9282, doi:10.5194 /acp-10-9251-2010.

Liu, Y. J., I. Herdlinger-Blatt, K. A. McKinney, and S. T. Martin, 2013: Production of methyl vinyl ketone and methacrolein via the hydroperoxyl pathway of isoprene oxidation. Atmos. Chem. Phys., 13, 5715-5730, doi:10.5194/acp-13-5715-2013.

— - and Coauthors, 2016: Isoprene photochemistry over the Amazon rainforest. Proc. Natl. Acad. Sci. USA, 13, 6125-6130, doi:10.1073/pnas.1524136113.

Machado, L. A. T., and Coauthors, 2014: The Chuva project: How does convection vary across Brazil? Bull. Amer. Meteor. Soc., 95, 1365-1380, doi:10.1175 /BAMS-D-13-00084.1.

Mares, M. A., 1986: Conservation in South America: Problems, consequences, and solutions. Science, 233, 734-739, doi:10.1126/science.233.4765.734.

Martin, S. T., and Coauthors, 2010a: Sources and properties of Amazonian aerosol particles. Rev. Geophys., 48, RG2002, doi:10.1029/2008RG000280.

— , and Coauthors, 2010b: An overview of the Amazonian Aerosol Characterization Experiment 2008 (AMAZE-08). Atmos. Chem. Phys., 10, $11415-$ 11 438, doi:10.5194/acp-10-11415-2010.

— , and Coauthors, 2016: Introduction: Observations and modeling of the Green Ocean Amazon (GoAmazon2014/5). Atmos. Chem. Phys., 16, 47854797, doi:10.5194/acp-16-4785-2016.

Mather, J. H., and J. W. Voyles, 2013: The ARM Climate Research Facility: A review of structure and capabilities. Bull. Amer. Meteor. Soc., 94, 377-392, doi:10.1175/BAMS-D-11-00218.1.
May, P. T., V. N. Bringi, and M. Thurai, 2011: Do we observe aerosol impacts on DSDs in strongly forced tropical thunderstorms? J. Atmos. Sci., 68, 1902-1910, doi:10.1175/2011JAS3617.1.

Perring, A. E., S. E. Pusede, and R. C. Cohen, 2013: An observational perspective on the atmospheric impacts of alkyl and multifunctional nitrates on ozone and secondary organic aerosol. Chem. Rev., 113, 5848-5870, doi:10.1021/cr300520x.

Poschl, U., and Coauthors, 2010: Rainforest aerosols as biogenic nuclei of clouds and precipitation in the Amazon. Science, 329, 1513-1516, doi:10.1126 /science.1191056.

Rangno, A. L., and P. V. Hobbs, 2005: Microstructures and precipitation development in cumulus and small cumulonimbus clouds over the warm pool of the tropical Pacific Ocean. Quart. J. Roy. Meteor. Soc., 131, 639-673, doi:10.1256/qj.04.13.

Reutter, P., and Coauthors, 2009: Aerosol- and updraftlimited regimes of cloud droplet formation: Influence of particle number, size and hygroscopicity on the activation of cloud condensation nuclei (CCN). Atmos. Chem. Phys., 9, 7067-7080, doi:10.5194/acp -9-7067-2009.

Roosevelt, T., 1914: Through the Brazilian Wilderness. Charles Scribner's Sons, 383 pp.

Rosenfeld, D., U. Lohmann, G. B. Raga, C. D. O’Dowd, M. Kulmala, S. Fuzzi, A. Reissell, and M. O. Andreae, 2008: Flood or drought: How do aerosols affect precipitation? Science, 321, 1309-1313, doi:10.1126 /science.1160606.

Salati, E., and P. B. Vose, 1984: Amazon basin: A system in equilibrium. Science, 225, 129-138, doi:10.1126 /science.225.4658.129.

Schmid, B., and Coauthors, 2014: The DOE ARM aerial facility. Bull. Amer. Meteor. Soc., 95, 723-742, doi:10.1175/BAMS-D-13-00040.1.

Silva Dias, P. L., D. S. Moreira, and G. D. Neto, 2006: The Master Super Model Ensemble System (MSMES). Eighth Int. Conf. on Southern Hemisphere Meteorology and Oceanography, Foz do Iguaçu, Brazil, Amer. Meteor. Soc., 1751-1757.

Stokes, G. M., and S. E. Schwartz, 1994: The Atmospheric Radiation Measurement (ARM) program: Programmatic background and design of the cloud and radiation test bed. Bull. Amer. Meteor. Soc., 75, 1201-1221, doi:10.1175/1520-0477(1994)075<1201: TARMPP $>2.0 . C O ; 2$.

ter Steege, H., and Coauthors, 2013: Hyperdominance in the Amazonian tree flora. Science, 342, doi:10.1126 /science.1243092.

Trebs, I., and Coauthors, 2012: Impact of the Manaus urban plume on trace gas mixing ratios near the 
surface in the Amazon basin: Implications for the $\mathrm{NO}-\mathrm{NO}_{2}-\mathrm{O}_{3}$ photostationary state and peroxy radical levels. J. Geophys. Res., 117, D05307, doi:10.1029/2011JD016386.

Unger, N., 2012: Global climate forcing by criteria air pollutants. Annu. Rev. Environ. Resour., 37, 1-24, doi:10.1146/annurev-environ-082310-100824.

Valin, L. C., A. R. Russell, and R. C. Cohen, 2013: Variations of $\mathrm{OH}$ radical in an urban plume inferred from $\mathrm{NO}_{2}$ column measurements. Geophys. Res. Lett., 40, 1856-1860, doi:10.1002/grl.50267.

Wendisch, M., and Coauthors, 2016: The ACRIDICON-CHUVA campaign: Studying tropical deep convective clouds and precipitation over Amazonia using the new German research aircraft HALO. Bull. Amer. Meteor. Soc., 97, 1885-1908, doi:10.1175/BAMS -D-14-00255.1.

Williams, E., and Coauthors, 2002: Contrasting convective regimes over the Amazon: Implications for cloud electrification. J. Geophys. Res., 107, 8082, doi:10.1029/2001JD000380.

Yuter, S. E., and R. A. Houze, 1995: Three-dimensional kinematic and microphysical evolution of Florida cumulonimbus. Part II: Frequency distributions of vertical velocity, reflectivity, and differential reflectivity. Mon. Wea. Rev., 123, 1941-1963, doi:10.1175/1520-0493(1995)123<1941:TDKAME $>2.0 . \mathrm{CO} ; 2$.

\section{NEW FROM AMS BOOKS!}

\section{"An engrossing account of New England's worst natural catastrophe." \\ - KeRry EMANUEL, Professor of Atmospheric Science, MIT}

\section{Taken by Storm, 1938:}

A Social and Meteorological History of the Great New England Hurricane LOURDES B. AVILÉS

When the Great New England Hurricane of 1938 hit the Northeast unannounced, it changed everything from the landscape, to Red Cross and Weather Bureau protocols, to the measure of Great Depression relief New Englanders would receive, and the resulting pace of regional economic recovery. The science behind this storm is presented here for the first time, with new data that sheds light on the motivations of the Weather Bureau forecasters. This compelling history successfully weaves science, historical accounts, and social analyses to create a comprehensive picture of the most powerful and devastating hurricane to hit New England to date.

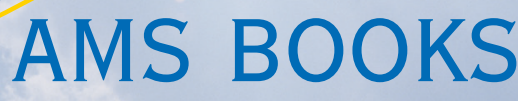

RESEARCH APPLICATIONS HISTORY WwW.ametsoc.org/amsbookstore 


\section{EYEWITNESS \\ EVolution of the AtMospheric Sciences}

\section{by ROBERT G. FLEAGLE}

Eyewitness: Evolution of the Atmospheric Sciences describes how the atmospheric sciences were transformed in the span of the author's professional career from its origins in primitive weather forecasting to its current focus on

numerical modeling of environmental change. It describes

the author's observations of persons, events, and institutions beginning with graduate study during the Second World War and moving on to continuing expansion of the atmospheric sciences and technologies, through development of a major university department, development of new

scientific and professional institutions, and to the role that the science of the atmosphere now plays in climate change and other issues of social and political policy.

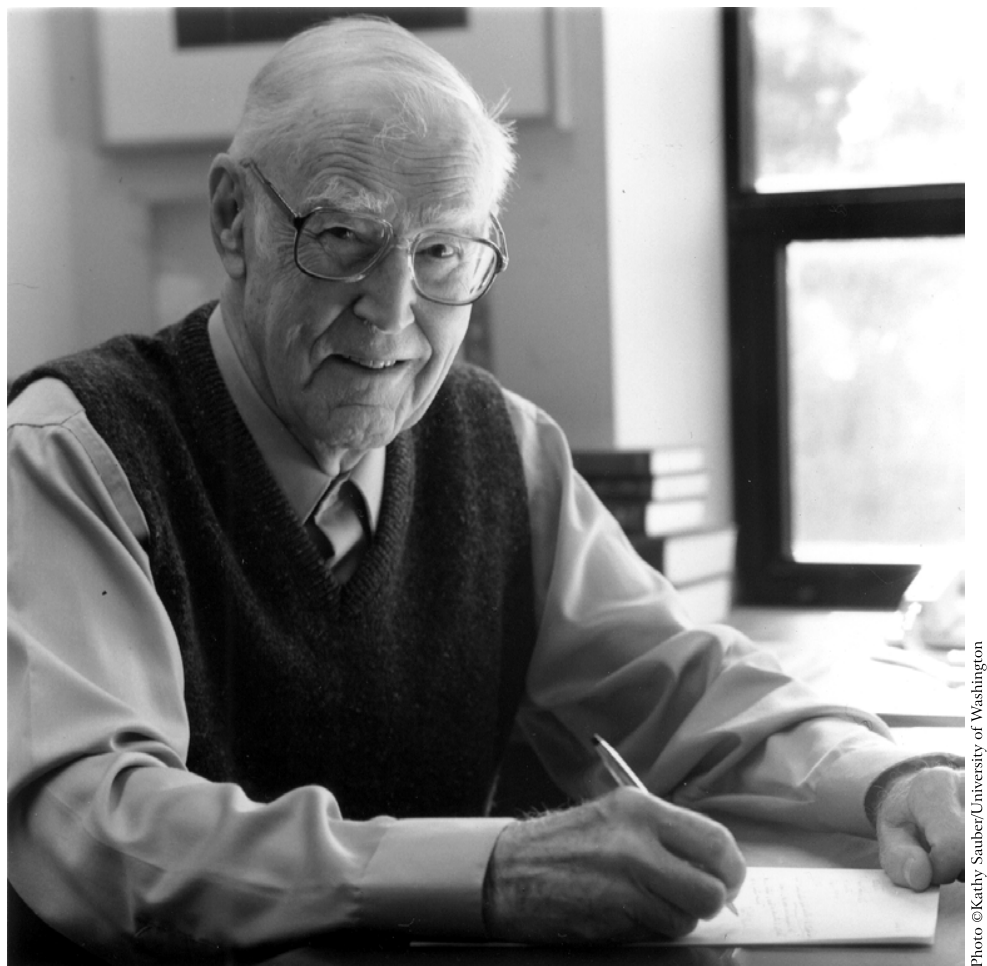

EYEWITNESS: EVOLUTION OF THE ATMOSPHERIC SCIENCES

ISBN 1-878220-39-X, 129 pp., hardbound, \$75 list/\$55 member.

Order online: www.ametsoc.org/amsbookstore

or see the order form at the back of this issue.

\section{ABOUT THE AUTHOR}

Robert G. Fleagle earned degrees in physics and meteorology at The Johns Hopkins University and New York University and began his professional career in 1948 at the University of Washington (UW). His research has focused on the structure of midlatitude cyclones, the physics and structure of the surface boundary layer, and processes of air-sea interaction. He is the author of about 100 papers published in scientific journals and of books on atmospheric physics and global environmental change. Applications of science to social and political policy have been important motivations for his career and have occupied his attention increasingly as the decades passed.

Fleagle participated at close range in the beginnings and growth of a major university department and of the University Corporation for Atmospheric Research (UCAR). In 1963 and 1964 he served as a staff specialist in the Office of Science and Technology, Executive Office of the President, and in 1977-78 he served as consultant to the National Oceanic and Atmospheric Administration. He has held many administrative posts including chairman of the UW Department of Atmospheric Sciences (1967-77), chairman of the National Academy of Sciences Committee on Atmospheric Sciences (1969-73), 